\title{
Exogenous Intake of Fluorides in Caries Prevention: Benefits and Risks
}

\author{
Romana Koberová Ivančaková1, Vladimíra Radochová1,*, Flóra Kovácsová1, Vlasta Merglová²
}

\section{ABSTRACT}

Caries incidence and prevalence have decreased significantly over the last few decades due to widespread use of fluoride. However, an increase in the prevalence of dental fluorosis has been reported in both fluoridated and non-fluoridated communities. Care must be taken to ensure that a balance between the optimal fluoride preventive effect at the individual and community level and minimal risk of dental fluorosis is maintained. This review describes the main sources of fluoride intake that have been identified: fluoridated drinking water, dietary fluoride supplement, and topical forms comprising toothpastes, rinses, gels and varnishes. The cited data were taken from metaanalytic studies and reports from Cochrane database systematic reviews up to December 2019. Efficiency, but safety, of topically applied fluorides in individual home care is dependent on the degree of compliance of individuals/parents and on the level of competence of providers of preventive counselling. The broad spectrum of these resources allows individualization of fluoride prevention based on risk analysis of caries attack and taking into consideration other preventive measures.

\section{KEYWORDS}

fluoride; systemic and topical fluoride prevention; dental caries; dental fluorosis

AUTHOR AFFILIATIONS

${ }^{1}$ Department of Dentistry, Faculty of Medicine, Charles University and University Hospital, Hradec Králové, Czech Republic

2 Department of Dentistry, Faculty of Medicine, Charles University and University Hospital, Pilsen, Czech Republic

* Corresponding author: Department of Dentistry, Faculty of Medicine, Charles University and University Hospital, Hradec Králové,

Czech Republic; vladimira.radochova@lfhk.cuni.cz

Received: 14 January 2021

Accepted: 28 February 2021

Published online: 30 July 2021

Acta Medica (Hradec Králové) 2021; 64(2): 71-76

https://doi.org/10.14712/18059694.2021.13

(c) 2021 The Authors. This is an open-access article distributed under the terms of the Creative Commons Attribution License (http://creativecommons.org/licenses/by/4.0), which permits unrestricted use, distribution, and reproduction in any medium, provided the original author and source are credited. 


\section{INTRODUCTION}

For over 60 years, dental professionals have been attempting to control caries with fluoride and its various inorganic and organic compounds (1). In the middle of the 20th century, it was believed that fluoride had to be incorporated into dental enamel during pre-eruptive stage of development to achieve its maximum protective effect. Ingestion of fluoride in the early years of life was considered essential for a full range of fluoride benefits to be achieved. It was assumed that incorporation of fluoride in the hydroxyapatite crystal during tooth formation and mineralization resulted in a permanent or long-lasting resistance to dental caries (2). However, it has been found that the fluoride-rich surface layer of the enamel, which was a result of systemic fluoride administration, was gradually lost because of insufficient post-eruptive maturation of enamel surface, and was unable to keep significant long-lasting protection against caries (3).

The recent view of our understanding of how fluoride works has been changed. The evidence suggests that the cariostatic effect of fluoride is mostly by its topical rather than systemic effect (3). This effect might be even greater when combined with tooth brushing with fluoride toothpastes. Based on both in vitro and in vivo studies it has been demonstrated that fluoride has a direct topical influence on the dynamic de- and re-mineralization processes that occur at the interface between the tooth surface and the adjacent dental biofilm (4).

\section{FLUORIDE BENEFITS AND CONCERNS}

Fluoride appears to provide its benefit when present at the plaque fluid during the caries challenge. Its effectiveness depends on how frequently it is administered in the oral cavity, and the mechanism of fluoride's topical anti-caries effect depends on the mode of application, its chemical formulation and, especially its concentration. Our current understanding of how fluoride affects tooth mineral and makes it more resistant in acidic environment has been reviewed extensively (5-7). The mechanism of action of fluoride includes the inhibition of demineralization on crystal surface, enhancement of remineralization on crystal surface, and inhibition of bacterial activity (8).

The concept of the topical application of fluorides became widely accepted as a key factor in successful caries prevention without significant ingestion of fluoride. Fluorides are also effective as therapeutic agents in non-invasive caries treatment for the inactivation or arrest of caries lesion $(9,10)$.

The concerns about the prevalence of dental fluorosis considered as the most frequently discussed risk of implementation of fluoride, has mostly been related to the use of fluoride supplements, especially during the first 6 years of life (11). Early exposure to fluoride toothpaste might also be a risk factor due to ingestion of toothpaste by small children $(12,13)$. The most important risk factor for dental fluorosis is the total amount of fluoride consumed from all sources during the critical period of tooth development. This critical period is the late secretion-early maturation stage of pre-eruptive dental enamel $(13,14)$.

\section{WHICH INDIVIDUALS ARE AT RISK?}

Small children under the age of 4 years are considered to be at risk of dental fluorosis of permanent incisors and permanent first molars. This period of life is known as the period of calcification and maturation of these teeth (15). The longitudinal Iowa study found that exposure to fluoride during the first 3 years of life was the most important for fluorosis development on the permanent maxillary incisors (16). The use of fluoride must be therefore carefully monitored and balanced. The prevention of early childhood caries on one hand and minimize the risk of dental fluorosis on the other hand should always been considered. The amount of fluoride intake from all potential sources has been calculated as 0.05-0.07 mg F/body weight/day as an optimal intake of fluoride, safe with respect of mild form of dental fluorosis and effective enough in caries prevention $(15,17,18)$. Special attention should be given to the use of topically applied fluoride gels and solution, because of the inadequate control of the swallowing.

In pre-school children up to 6 years may develop dental fluorosis of posterior teeth (premolars and second molar). Nevertheless, it presents less of an aesthetic problem, which needs to be weighed against the marked benefit of fluorides in caries prevention of primary and young permanent teeth. The risk of dental fluorosis in school children older than 6 years is very small (19).

\section{SOURCES OF FLUORIDE INTAKE}

Concern about dental fluorosis and its potential impact on quality of life should be taken into consideration. Therefore, all forms of fluoride intake from all sources should be calculated, especially in children. Fluoride prevention and prophylaxis against dental caries is commonly divided to topical and systemic. Topical agents as fluoridated toothpaste, fluoride gels, solutions and varnishes, are applied onto to enamel surface of erupted teeth. Systemic application (water, milk, salt, supplements) of fluorides brings fluoride compounds to GIT, where they are absorbed and in blood way they get into hard dental tissues of developing teeth. The less amount of fluoride gets into saliva and oral environment. Topically applied fluorides can be unintentionally swallowed and therefore increase the alimentary ingested fluorides.

\section{FLUORIDATED DRINKING WATER}

Community water fluoridation (CWF) was introduced over 70 years ago as a public health measure to prevent and control caries at a population level. A great advantage of CWF it that it benefits all residents in a community, regardless age, socio-economic status, education, oral hygiene practice or access to routine dental care (8). CWF is 
also a cost-effective method of delivering caries prevention to a large population (20). The fluoride concentration of water in CWF programs typically ranges from 0.5 to $1.1 \mathrm{mg} \mathrm{L}^{-1}$ (ppm F). A recent Cochrane review estimated that the initiation of CWF reduced caries levels by $35 \%$ in the primary dentition and $26 \%$ in the permanent dentition of children. The review also found that CWF led to a $15 \%$ increase of children with caries-free primary teeth and a $14 \%$ increase of children with caries-free permanent teeth, compared to children without water fluoridation (21). CWF has its place in economic disadvantaged communities with low level of health literacy. After all, fluoridated water is nowadays consumed by a half of billions of people worldwide (21).

Several recent reviews on the impact of fluoridated water on human health have been published (21-23). Positive effect of CWF is significant also when combined with other forms of fluoridation. No reliable evidence for any health risk associated with the use of fluoridated water at the recommended level was found. The mild form of dental fluorosis is the only unwanted effect associated with CWF. The Cochrane review of water fluoridation estimated the $12 \%$ prevalence of dental fluorosis of aesthetic concern at fluoride levels of $0.7 \mathrm{mg} \mathrm{L}^{-1}(\mathrm{ppm} \mathrm{F})$ in drinking water (21).

There is the evidence of increasing consumption of bottled drinking water during the last two decades in form of spring water or mineral water. Alimentary consumed water in any form represents almost $80 \%$ of alimentary ingested fluoride (24). Some of mineral waters contain fluoride in similar concentration as recommended amount of fluoride in CWF and therefore this source of fluoride should be considered as a significant alimentary fluoride intake.

\section{FLUORIDATED MILK}

Milk fluoridation has been reported to be successful in dental caries prevention, particularly in children as a community preventive programs in form of milk snacks $(23,25)$. This community measure is supported by WHO in all global documents focused on caries prevention (26). The fluoridated milk is distributed in $200 \mathrm{ml}$ packs containing $5 \mathrm{ppm}$ fluoride, what corresponds to $1 \mathrm{mg}$ of fluoride in the pack. The effect of fluoridated milk has been evaluated on the groups of children in Great Britain, Hungary, China, Peru and Thailand. The results of the meta-analytic study from these countries published in Cochran review reported $43-85 \%$ reduction of caries incidence in permanent dentition, but less significant results in primary dentition (27). Repeated studies on Bulgarian children have confirmed $40 \%$ caries reduction in primary dentition when the beginning of fluoridated milk consumption was at 3-3.5 years. Additionally, these studies have found the comparable effect of fluoridated milk with fluoridated water if number of daily doses exceeds 160 per year (28). Recently fluoridated milk is extensively used in Russian Federation, Great Britain, China and Bulgaria. The administration of fluoridated milk in children older than 3 years of age is regarded as the safe preventive method from the point of view of its ratio on total alimentary fluoride intake (26). No potential adverse effect of fluoridated milk was found (27). A high concentration of fluoride in milk $\left(5 \mathrm{mg} \mathrm{L}^{-1}\right)$ is needed for two reasons: children did not drink the beverage throughout the day and calcium in the milk complexes with fluoride, which would reduce its availability for topical benefit (27).

\section{FLUORIDATED SALT}

Fluoridated salt was firstly introduced in Switzerland in the middle of the last century on the basis of good experience with iodized salt. The number of successful clinical studies resulted in recommendation of fluoridated salt as the systemic forms of caries prevention (29), (30). The fluoride content in salt varies from $250-350 \mathrm{mg} \mathrm{F} / \mathrm{kg}$ in most countries, where this method was approved for the individual home use. The meta-analytic studies in school children lasting more than three years reported the significant caries decline in permanent dentition compared to control (non-fluoridated salt group) with Odds ratio from -2.13 to $-4.22(31,32)$. The effect of fluoridated salt on primary dentition in pre-school children is not significant. The concern of excessive alimentary intake of fluoride from salt with the combination of other forms of systemic administration of fluorides is low in the view of the fact that recent dietary advice lead to minimize the exposure to salt from diet in small children (33).

\section{FLUORIDE SUPPLEMENTS \\ (TABLETS, LOZENGES AND DROPS)}

Fluoride supplements were first introduced to provide systemic fluoride in areas where water fluoridation was not available. Supplements contain a measured amount of fluoride, typically $0.25 \mathrm{mg}, 0.5 \mathrm{mg}$, or $1.0 \mathrm{mg}$, usually as sodium fluoride, acidulated phosphate fluoride, potassium fluoride, or calcium fluoride (34). There are few data on the extent to which these products are used, but they are known to have widespread use as a caries preventive for children. The post-eruptive efficacy of fluoride supplements has been demonstrated in school children, though the original rationale for their use, i.e. pre-eruptive uptake by developing enamel to form a more resistant tooth is no longer tenable. Additionally, when using them, care should be taken that the products have sufficient substantive topical effect in oral cavity (34). The recommendation of use of fluoride supplements varies from country to country. The most of experts has very restrained view on fluoride supplements and they recommend this form of caries preventive method in children older than three years of age with high caries risk because of risk of dental fluorosis and low parental compliance in regular, daily administration of the supplements $(35,36)$. The systematic reviews published by Ismail AI, 2008 evaluated the results of 20 longitudinal studies. They concluded the effect of fluoride tablets in the reduction of caries incidence in permanent dentition up to $43 \%$ but with the mild risk of dental fluorosis (OR 1.8-2.2). The preventive effect of fluoride supplements in primary dentition is still controversial because of 
low level of evidence and confirmed risk of dental fluorosis in permanent dentition (11). The results from the panel of experts, entitled "European view of fluoride supplementation" reached the consensus on the necessity 1) to indicate fluorides supplements administration strictly to the back ground fluoride intake from food and beverages, 2) to start with fluoride supplementation (if necessary) at the age of 3 years, 3) to take fluoride supplementation by no means as a wide spread preventive measure (34).

\section{FLUORIDE TOOTHPASTE}

Fluoride toothpastes were introduced in the late 1960s and early 1970s and their rapid and remarkable increase on the market share was followed by massive reduction in dental caries seen in many countries over the past 40 years (37). Tooth brushing with fluoride toothpaste is close to an ideal public health method being convenient, inexpensive, culturally approved and widespread. Within the meaning of fluoride caries prevention, tooth paste is understood as a carrier of fluoride which increasing the fluoride concentration in oral cavity during the tooth brushing, increasing the overall amount of fluoride in oral environment what leads to enhancing remineralization, inhibiting demineralization and some metabolic processes of oral bacteria (38). The number of systematic reviews confirmed the positive effect of fluoride toothpaste in the last decades (38-43). The systematic review of Twetman reported the $24 \%$ decline of caries incidence in children (39). The meta-analytic study of 76 published randomized studies in children and adolescents published by Walsh et al. 2010 confirmed the 19-27\% increasing caries reduction with the arising fluoride concentration in the tooth pastes (43). There is a substantial concern that small children during the tooth brushing with fluoride tooth paste swallow some paste with a subsequent risk of fluorosis (41). Fluoride toothpaste may be responsible for up to $80 \%$ of the "optimal" total daily intake of fluoride in children below 3 years of age (44). Therefore, parents must be strongly advised to assist and supervise tooth brushing until at least 7 years of age. The amount of tooth paste applied onto the tooth brush must be age-related and parents of pre-school children should not allow them to do it alone. There is a little evidence of effectiveness of the toothpaste with fluoride concentration less than $1000 \mathrm{ppm} F$ in caries prevention in older pre-school (4-5 years) and school children particularly in those in caries risk (43). The recommended fluoride concentration in tooth pastes is presented in table 1.

\section{FLUORIDE GELS, RINSES, VARNISHES}

Except of tooth pastes, other topically applied agents are considered effective especially in children at high caries risk, including children with special oral health care needs or under orthodontic treatment particularly when permanent teeth start to erupt. Fluoride rinses recently recommended as the supplementary measure in caries prevention contain 200-900 ppm fluoride in form of sodium fluoride or aminfluoride. The lower concentration, usually 225-250 ppm fluoride is recommended for daily use, those with $900 \mathrm{ppm}$ fluoride are used weekly, in caries risk children older than 8 years of age. Children are advised to use them after the tooth brushing to prolong the increased amount of fluoride in oral cavity. They are not recommended in children below 6 years of age because of risk of swallowing what may lead to increased fluoride plasma levels and mild risk of dental fluorosis. The several meta-analytic studies have been reported and the effect of fluoride rinses have been clinically studied (44-46). Twetman et al., 2004 evaluated the data from 24 studies and found the $29 \%$ reduction of caries increment both in case of daily rinse containing $225 \mathrm{ppm}$ fluoride and weekly rinse containing 900 ppm fluoride (47). It can be concluded that rinses are reported as effective in permanent teeth (20-50\% caries reduction) but no data are available in primary teeth (45). Fluoride gels in caries prevention are used more than 50 years. Formerly they were used for professional application in dental office, recently are also recommended for home use as $2 \%$ sodium fluoride, $1.23 \%$ acidulated fluorophosphates and combination of $0.25 \%$ aminfluoride $+1 \%$ sodium fluoride. Several meta-analytic studies have confirmed their preventive effect in permanent dentition ranging from $28-37 \%$ in reduction of caries increment $(46,48,49)$. The effect of gels in primary teeth is uncertain. Especially, in pre-school children, the risk of ingestion and subsequent dental fluorosis should be weighed against the potential caries-preventive benefit. Fluoride varnishes contain $1-5 \%$ sodium fluoride $(22,600 \mathrm{ppm} F)$ as resin or synthetic formula. They are for professional use only. Varnish as the only high fluoride topical agent can be used in both pre-school and school children with the caries reduction $50-70 \%$ (50). They are applied on clean and dry enamel surface 3-4 per year particularly in high caries risk children. They serve also as the prophylactic agent in initial subsurface lesions (9). There is a moderate evidence of its efficacy with minimal risk of dental fluorosis, because once it sets to hard, it cannot be swallowed (44).

Tab. 1 Recommended use of fluoride toothpaste in children.

\begin{tabular}{|c|c|c|c|c|}
\hline Age of the child & Fluoride concentration (ppm F) & Frequency & Amount of toothpaste $(\mathbf{g})$ & Size \\
\hline First tooth up to 2 years & 1000 & Twice daily & 0.125 & Grain of rise \\
\hline 2-6 years & $1000^{*}$ & Twice daily & 0.25 & Pea \\
\hline Over 6 years & 1450 & Twice daily & $0.5-1.0$ & Up to full length of the brush \\
\hline
\end{tabular}

* In caries risk children $1000+$ ppm $\mathrm{F}$ is recommended based on the caries risk assessment.

Adopted from: (19) 


\section{CONCLUSIONS}

This literature review presents the evidences supporting the current strategy of fluoride use in caries prevention and its potential risk, particularly in children. Where fluoride is used in conjunction with other fluoride vehicles, the cumulative fluoride exposure must be taken into consideration for children less than 6 years of age. Care must be taken to ensure that a balance between the optimal preventive effect and minimal risk of dental fluorosis is maintained. On the other hand the recent recommendations of fluoride use are as safe as can be, but dependent on the degree of compliance of individuals, respectively parents of children and on the level of competence of providers of preventive counselling. The broad spectrum of these resources allows individualization of fluoride prevention based on risk analysis of caries attack and taking into consideration other preventive measures.

Based on the scientific evidence and current literature data, authors strongly support the recommended use of fluoride in paediatric population and adopt them by both paediatric and paediatric dentistry community.

\section{AUTHOR CONTRIBUTIONS}

RKI, VR, FK and VM equally contributed to the design of the review, RKI, VR and FK writing the original draft, VM revised the draft.

\section{DECLARATION OF INTEREST STATEMENT}

All authors declare that they have no conflict of interest regarding the publication of this manuscript.

\section{ACKNOWLEDGEMENTS}

The study was supported by the program PROGRES Q 29, and by the grant MH CZ - DRO (UHHK, 00179906).

\section{REFERENCES}

1. Ripa LW. A half-century of community water fluoridation in the United States: review and commentary. J Public Health Dent 1993; 53(1): 17-44.

2. Fejerskov O, Thylstrup A, Larsen MJ. Rational use of fluorides in caries prevention. A concept based on possible cariostatic mechanisms. Acta Odontol Scand 1981; 39(4): 241-9.

3. Featherstone JD. Prevention and reversal of dental caries: role of low level fluoride. Community Dent Oral Epidemiol 1999; 27(1): 31-40.

4. Fejerskov $\mathrm{O}$. Changing paradigms in concepts on dental caries: consequences for oral health care. Caries Res 2004; 38(3): 182-91.

5. ten Cate JM. Current concepts on the theories of the mechanism of action of fluoride. Acta Odontol Scand 1999; 57(6): 325-9.

6. Robinson C, Shore RC, Brookes SJ, Strafford S, Wood SR, Kirkham J. The chemistry of enamel caries. Crit Rev Oral Biol Med Off Publ Am Assoc Oral Biol 2000; 11(4): 481-95.

7. Robinson C. Fluoride and the caries lesion: interactions and mechanism of action. Eur Arch Paediatr Dent Off J Eur Acad Paediatr Dent 2009; 10(3): 136-40.

8. Buzalaf MAR, Levy SM. Fluoride intake of children: considerations for dental caries and dental fluorosis. Monogr Oral Sci 2011; 22: 1-19.

9. Slayton RL, Urquhart O, Araujo MWB, et al. Evidence-based clinical practice guideline on nonrestorative treatments for carious lesions:
A report from the American Dental Association. J Am Dent Assoc 1939. 2018; 149(10): 837-849.e19.

10. Urquhart O, Tampi MP, Pilcher L, Slayton RL, Araujo MWB, Fontana $M$, et al. Nonrestorative Treatments for Caries: Systematic Review and Network Meta-analysis. J Dent Res 2019; 98(1): 14-26.

11. Ismail AI, Bandekar RR. Fluoride supplements and fluorosis: a meta-analysis. Community Dent Oral Epidemiol 1999; 27(1):48-56.

12. Levy SM, Kiritsy MC, Warren JJ. Sources of fluoride intake in children. J Public Health Dent 1995; 55(1): 39-52.

13. Wong MC, Glenny A-M, Tsang BW, Lo EC, Worthington HV, Marinho VC. Topical fluoride as a cause of dental fluorosis in children. Cochrane Database Syst Rev 2010 Jan 20; 2010(1): CD007693.

14. DenBesten PK. Biological mechanisms of dental fluorosis relevant to the use of fluoride supplements. Community Dent Oral Epidemiol 1999; 27(1): 41-7.

15. Hong L, Levy SM, Warren JJ, Broffitt B, Cavanaugh J. Fluoride intake levels in relation to fluorosis development in permanent maxillary central incisors and first molars. Caries Res 2006; 40(6): 494-500.

16. Levy SM, Kiritsy MC, Slager SL, Warren JJ. Patterns of dietary fluoride supplement use during infancy. J Public Health Dent 1998; $58(3): 228-33$

17. Burt BA. The changing patterns of systemic fluoride intake. J Dent Res 1992; 71(5): 1228-37.

18. Whelton HP, Ketley CE, McSweeney F, O'Mullane DM. A review of fluorosis in the European Union: prevalence, risk factors and aesthetic issues. Community Dent Oral Epidemiol 2004; 32(Suppl 1): 9-18.

19. Toumba KJ, Twetman S, Splieth C, Parnell C, van Loveren C, Lygidakis NA. Guidelines on the use of fluoride for caries prevention in children: an updated EAPD policy document. Eur Arch Paediatr Dent Off J Eur Acad Paediatr Dent 2019; 20(6): 507-16.

20. Ran T, Chattopadhyay SK, Community Preventive Services Task Force. Economic Evaluation of Community Water Fluoridation: A Community Guide Systematic Review. Am J Prev Med 2016; 50(6): 790-6.

21. Iheozor-Ejiofor $Z$, Worthington HV, Walsh T, et al. Water fluoridation for the prevention of dental caries. Cochrane Database Syst Rev 2015 Jun 18; 2015(6): CD010856.

22. McDonagh MS, Whiting PF, Wilson PM, et al. Systematic review of water fluoridation. BMJ 2000; 321(7265): 855-9.

23. Jürgensen N, Petersen PE. Promoting oral health of children through schools--results from a WHO global survey 2012. Community Dent Health 2013; 30(4): 204-18.

24. Buzalaf MAR, Levy SM. Fluoride intake of children: considerations for dental caries and dental fluorosis. Monogr Oral Sci 2011; 22: $1-19$.

25. Espelid I. Caries preventive effect of fluoride in milk, salt and tablets: a literature review. Eur Arch Paediatr Dent Off J Eur Acad Paediatr Dent 2009; 10(3): 149-56.

26. Bánóczy J, Rugg-Gunn A, Woodward M. Milk fluoridation for the prevention of dental caries. Acta Medica Acad 2013; 42(2): 156-67.

27. Yeung CA, Chong LY, Glenny A-M. Fluoridated milk for preventing dental caries. Cochrane Database Syst Rev 2015 Sep 3; 2015(9): CD003876.

28. Ivanova K, Pakhomov GN, Moeller IJ, Vrabcheva M. Caries reduction by milk fluoridation in Bulgaria. Adv Dent Res 1995; 9(2): 120-1.

29. Petersen PE, Lennon MA. Effective use of fluorides for the prevention of dental caries in the 21 st century: the WHO approach. Community Dent Oral Epidemiol 2004; 32(5): 319-21.

30. Marthaler TM, Petersen PE. Salt fluoridation - an alternative in automatic prevention of dental caries. Int Dent J 2005; 55(6): 351-8.

31. Yengopal V, Chikte UME, Mickenautsch S, Oliveira LB, Bhayat A. Salt fluoridation: a meta-analysis of its efficacy for caries prevention. SADJ J South Afr Dent Assoc Tydskr Van Suid-Afr Tandheelkd Ver 2010; 65(2): 60-4, 66-7.

32. Yeung CA. Efficacy of salt fluoridation. Evid Based Dent 2011; 12(1): 17-8.

33. Pollick HF. Salt fluoridation: a review. J Calif Dent Assoc 2013; 41(6): 395-7, 400-4.

34. Clarkson J. A European view of fluoride supplementation. Br Dent J 1992; $172(9): 357$.

35. Ismail AI, Hasson H. Fluoride supplements, dental caries and fluorosis: a systematic review. J Am Dent Assoc 1939. 2008; 139(11): 1457-68.

36 . Horowitz HS. The role of dietary fluoride supplements in caries prevention. J Public Health Dent 1999; 59(4): 205-10.

37. Marthaler TM. Changes in dental caries 1953-2003. Caries Res 2004; 38(3): 173-81.

38. Marinho VC, Higgins JP, Sheiham A, Logan S. Fluoride toothpastes for preventing dental caries in children and adolescents. Cochrane Database Syst Rev 2003; 2003(1): CD002278.

39. Twetman S, Axelsson S, Dahlgren H, et al. Caries-preventive effect of 
fluoride toothpaste: a systematic review. Acta Odontol Scand 2003; 61(6): 347-55.

40. Twetman S. Caries prevention with fluoride toothpaste in children: an update. Eur Arch Paediatr Dent Off J Eur Acad Paediatr Dent 2009; 10(3): 162-7.

41. Wong MCM, Clarkson J, Glenny A-M, et al. Cochrane reviews on the benefits/risks of fluoride toothpastes. J Dent Res 2011; 90(5): 573-9.

42. Wright JT, Hanson N, Ristic H, Whall CW, Estrich CG, Zentz RR. Fluoride toothpaste efficacy and safety in children younger than 6 years: a systematic review. J Am Dent Assoc 1939. 2014; 145(2): 182-9.

43. Walsh T, Worthington HV, Glenny A-M, Marinho VC, Jeroncic A. Fluoride toothpastes of different concentrations for preventing dental caries. Cochrane Database Syst Rev 2019 Mar 4; 3(3): CD007868.

44. Marinho VCC, Worthington HV, Walsh T, Clarkson JE. Fluoride varnishes for preventing dental caries in children and adolescents. Cochrane Database Syst Rev 2013 Jul 11; 2013(7): CD002279.
45. Marinho VCC, Chong LY, Worthington HV, Walsh T. Fluoride mouthrinses for preventing dental caries in children and adolescents. Cochrane Database Syst Rev 2016 Jul 29; 2016(7): CD002284.

46. Twetman S, Keller MK. Fluoride Rinses, Gels and Foams: An Update of Controlled Clinical Trials. Caries Res 2016; 50(Suppl 1): 38-44.

47. Twetman S, Petersson L, Axelsson S, et al. Caries-preventive effect of sodium fluoride mouthrinses: a systematic review of controlled clinical trials. Acta Odontol Scand 2004; 62(4): 223-30.

48. Marinho VCC. Cochrane reviews of randomized trials of fluoride therapies for preventing dental caries. Eur Arch Paediatr Dent Off J Eur Acad Paediatr Dent 2009; 10(3): 183-91.

49. Marinho VCC, Worthington HV, Walsh T, Chong LY. Fluoride gels for preventing dental caries in children and adolescents. Cochrane Database Syst Rev 2015 Jun 15; 2015(6): CD002280.

50. Poulsen S. Fluoride-containing gels, mouth rinses and varnishes: an update of evidence of efficacy. Eur Arch Paediatr Dent Off J Eur Acad Paediatr Dent 2009; 10(3): 157-61. 